\title{
Cultura visual pentecostal: história visual e papel eclesial do cartaz dispensacionalista “O plano divino através dos séculos" de $1943{ }^{1}$ Pentecostal visual culture: visual history and
ecclesial role of the dispensational poster
The divine plan through the centuries" from 1943
}

Eric de Oliveira Martins ${ }^{2}$

Helmut Renders ${ }^{3}$

\begin{abstract}
RESUMO
O cartaz dispensacionalista "O plano divino através dos séculos" criado por Nelson Lawrence Olson em 1943 é um exemplo essencial da cultura visual pentecostal brasileira. O artigo foca na história visual do cartaz e no papel aplicado a ele, incialmente, na Igreja Assembleia de Deus, depois em outras vertentes do pentecostalismo brasileiro. Afirma-se, primeiro, que, a cultura visual pentecostal brasileira bebe de fontes estadunidenses pentecostais e darbistas, segundo, se comunica com teorias presbiterianos e jesuítas e, terceiro, assumiu um papel educacional fundamental nas igrejas pentecostais e outras igrejas. "O plano
\end{abstract}

\footnotetext{
${ }^{1}$ Esse artigo dialoga com resultados parciais da dissertação MARTINS, Eric de Oliveira. Cultura visual pentecostal: presença e uso do Quadro "o plano divino através dos séculos numa igreja Assembleia de Deus de 2019. 149f. Dissertação (Mestrado em Ciências da Religião) Universidade Metodista de São Paulo, Bernardo do Campo, SP, orientada por Helmut Renders. Essa dissertação contou com fomento da CAPES, bolsa taxa de fevereiro 2017 até janeiro 2019.

2 Mestre em Ciências da Religião pela UMESP.

3 Professor Associado I da UMESP, atuando no curso bacharel em teologia e no Programa de Pós-Graduação em Ciências da Religião. A dissertação foi orientada dentro do projeto de pesquisa A cultura visual evangélica: o surgimento, financiado pela Fundação de Amparo à Pesquisa do Estado de São Paulo (FAPESP) como Projeto regular entre setembro 2017 e agosto 2019.
} 
divino através dos séculos" pode ser considerado um dos três ícones da cultura visual protestante e pentecostal brasileira do século 20, das quais somente dois estão ainda em uso, ambas nas Assembleias de Deus.

\title{
PALAVRAS-CHAVE
}

Linguagens da Religião. Cultura Visual Religiosa. Assembleia de Deus. Quadro O Plano Divino Através dos Séculos.

\begin{abstract}
The dispensational poster "The Divine Plan Through the Ages" created by Nelson Lawrence Olson in 1943 is an essential example of Brazilian Pentecostal visual culture. The article focuses on the visual history of the poster and the role applied to it, initially, in the Assembly of God Church, and then on other aspects of Brazilian Pentecostalism. First, it is stated that, the Brazilian Pentecostal visual culture drinks from Pentecostal and Doodle American sources, secondly, it communicates with Presbyterian and Jesuit theories and, third, it has assumed a fundamental educational role in the Pentecostal, and other churches. Thus, "The divine plan through the centuries" can be considered one of the three icons of the 20th century Protestant and Pentecostal visual culture of Brazil, of which only two are still in use, both in the Assemblies of God.
\end{abstract}

\section{KEYWORDS}

Languages of Religion. Religious Visual Culture. Assembly of God. The Divine Plan through the Ages.

\section{Introdução}

O cartaz dispensacionalista $O$ plano divino através dos séculos - daqui para frente $P D a d S$ - é um importante exemplo da cultura visual pentecostal plenamente integradas nas práticas religiosas e, frequentemente, em uso nas igrejas assembleianas até hoje. Em distinção de outros estudos brasileiros ${ }^{4}$ fo-

4 FERREIRA, Maycon Sanches; OLIVEIRA, Vilmar Diniz; OLIVEIRA, David Mesquiat; SERENO, Samuel Goulart; SOUSA, Antonio Junio Alves de. "O Dispensacionalismo 
ca-se neste artigo na história da sua linguagem religiosa visual e no papel que esse plano ganhou aos pouco depois da sua introdução em 1943 nas Assembleias de Deus, base da afirmação que se trata de um dos três ícones da cultura visual evangélica ${ }^{5}$, protestante e pentecostal, do século 20. Em distinção dos outros "ícones", o PDadS pertence à terceira fase da cultura visual evangélica, já que não se trata de uma mera reprodução de uma obra do exterior, sem tradução (primeira fase) ou com tradução (segunda fase), mas de uma obra feita no Brasil para o Brasil, mais exatamente, na transição da segunda para a terceira fase ${ }^{6}$. Em seguida, vamos, primeiro, apresentar a história visual do PDadS. O intuito dessa parte é demonstrar que o pentecostalismo desde a sua origem, no início do século 20, se apropriava de linguagens religiosas visuais, parcialmente já introduzidas pelos adventistas a partir de 1843, especialmente para comunicar uma das suas doutrinas mais especificas ${ }^{7}$, o seu ensino apocalíptico e dispensacionalista. Na segunda parte, pretendemos sustentar a tese não somente da existência, mas da importância da cultura visual no pentecostalismo pela descrição do uso do PDadS nas Assembleias de Deus e outras igrejas pentecostais, bem como esse uso descreve a evolução do próprio PDadS de um encarte de um livro que ilustra o seu texto em preto branco para um cartaz exposto nas paredes para usá-lo no

no Pentecostalismo Brasileiro: Introdução ao Estudo de Recepção da Obra O Plano Divino Através dos Séculos". Unitas - Revista Eletrônica de Teologia e Ciências das Religiões, Vitória-ES, v. 4, n. 2, 2016, p. 155-172.

5 Usamos a palavra aqui num sentido mais coloquial. As qualidades de um ícone evangélico brasileiro da cultura visual ganharam, segundo a nossa observação mais duas obras. O mais antigo ícone da cultura visual evangélica brasileira é o Livrinho de Coração da autoria de Johann Evangelista Gossner (1822) com edições brasileiras - na sequência do seu lançamento - presbiterianas (1914), luteranas (1930), assembleianas (1950) metodistas (1970), e batistas (1990). O cartaz Os dois caminhos, criado em 1867 pela pietista Charlotte Reihlen, e introduzido pelos presbiterianos no Brasil em 1934 em sua versão inglesa e em uso nas Igrejas do Protestantismo histórico brasileiro até a década 70 do século passado, consideramos o segundo ícone da cultura visual evangélica brasileira.

${ }^{6}$ Considerando que seu autor, Olson, era estadunidense que trabalhou como missionário no Brasil, trata-se de um certo "entre a segunda e a terceira fase". Isso encaixa muito bem com a periodização geral proposta por nós.

7 A segunda doutrina especifica seria o ensino a respeito do batismo no ou pelo Espírito Santo. 
ensino dos membros da igreja e dos/as ingressos/as, agora independente do texto. O PDadS se tornou uma imagem usada no cotidiano da Igreja com tanta frequência que, aparentemente, ninguém problematiza hoje o uso dessa expressão da cultura visual.

\section{História visual do cartaz dispensacionalista “O plano divino através dos séculos" de 1943}

Quando Lawrence Nelson Olson publicou, em 1943, o livro O plano divino através dos séculos, ele continha um cartaz, o PDadS, com o mesmo título (figura 1$)^{8}$.

Figura 1: Olson, L. N. O plano divino através dos séculos, 1943 [cartaz] $]^{9}$

44

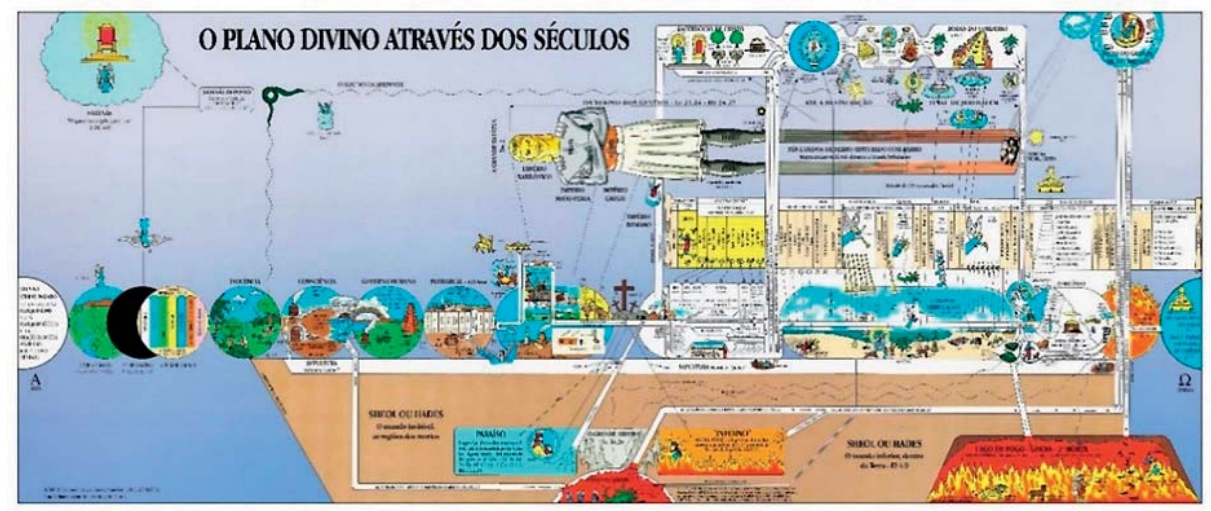

A origem da teoria dispensacionalista e das suas primeiras visualizações é geralmente traçado até John Nelson Darby (1800-1882) e seus

8 OLSON, Lawrence Nelson. O Plano Divino Através dos Séculos. Lavras, MG: [s.e.], 1943. As imagens nesse artigo servem, em primeiro lugar, para a identificação e distinção de gráficas, esquemas ou cartazes dispensacionalistas. Já no artigo paralelo - veja o rodapé n. 7 - vamos focar em detalhes.

9 OLSON, Nelson Lawrence. O plano divino através dos séculos, 1943 [cartaz]. Casa Publicadora da Assembleia de Deus (CPAD); Do acervo pessoal dos autores. 
seguidores. Entretanto, documenta David Morgan ${ }^{10}$ um esquema presbiteriano do século 17 que se refere a dispensações:

Espiritualidade puritana é muitas vezes considerada inimiga em relação à visualidade, mas na verdade ele gira em torno de atos de visão entendidos no registro do tempo. Os puritanos na Europa e na América, ambos, usaram as imagens nesta perspectiva e suas imagens refletem consistentemente a dimensão temporal ${ }^{11}$.

O desenho mencionado é do livro Chave da Apocalipse, de Jospeh Mede (1643).

Nele foi incluído um diagrama intitulado "Plano apocalíptico". O diagrama e o livro que ele ilustrou apresenta uma interpretação do Apocalipse, que traça profeticamente o curso do tempo até a contemporaneidade numa perspectiva da proximidade do fim. Mede calculou isso ao alinhar expressões proféticas, visões, símbolos e números com eventos históricos, situando o passado em relação à idade atual ${ }^{12}$.

Desenhos com projeções com esquemas temporais são, então, antigos, mesmo que ainda não incluíam nos esquemas simbolizações figurativas $^{13}$. Isso também era o caso de Darby, que não apenas usou visualizações

${ }^{10}$ MORGAN, David. The forge of vision: a visual history of modern Christianity. Oakland: University California Press, 2015. p. 93.

11 MORGAN, 2015, p. 92.

12 MORGAN, 2015, p. 92.

13 Os Jesuítas Ribeira e Bellarmine, e com eles os Jesuítas Blasius Viegas e Cornélio Lápide, criaram também sistemas futuristas que troxeram consigo de forma embrionária a ideia do arrebatamento pré-tribulacionista, posteriormente defendida por Darby, e que aparece na teoria dispensacionalista pré-milenista. Criou-se uma uma sistematização escatológica sobre como apareceria o anticristo no mundo e lançaram vários livros e tratados. Esses tratados foram aderidos por protestantes do século XIX, e o principal deles, John Nelson Darby. "E, por estranho que pareça, no século XIX este sistema escatológico, de origem jesuíta, veio a ser aceito por um crescente número de teólogos protestantes na Inglaterra, dos quais o mais expressivo foi João Nelson Darby, pastor anglicano, que, lá pelo ano 1830, obteve a adesão dos "Irmãos de Plymouth", que ficaram desde então conhecidos como Darbistas" (SACHALY, Harald. O Pré-milenismo Dispensacionalista à luz do Amilenismo. 2 ed. Rio de Janeiro: Junta de Educação Religiosa e Publicações, 1987, p. 13). 
figurativas ou simbólicas, mas também esquemas gráficos. Isso mudou, porém, com o adventista William Miller (1782-1849). Ele criou, no fim da sua vida, em 1843, ou seja, 13 anos depois da formação do grupo de darbistas, Um gráfico cronológico das visões de Daniel e João, onde aparece, pela primeira vez, cálculos com convergências com os dados da vida de pessoas mais contemporâneas, que resultava numa indicação do ano do retorno do Cristo (figura 2). Como Novaes ${ }^{14}$ recentemente destacou, 20 anos post mortem houve uma adaptação do gráfico cronológico pelo pastor adventista James White (1821-1881), no qual as passagens textuais tinham sidos drasticamente reduzidas, dando mais espaço ao aspecto visual. Assim, começou a relação estreita entre gráficos, planos, mapas e esquemas cronológicos com motivos figurativos e a promoção da doutrina dispensacionalista.

${ }^{14}$ NOVAES, Allan Macedo de. In: "Uma breve história da cultura visual adventista nos anos 1830 a 1860: o uso de imagens religiosas por um movimento de orientação textocentrada". Numen, revista de estudos e pesquisa da religião, Juiz de Fora, RJ, 2018, p. 38-61. 
Figura 2: William Miller, A chronological chart of the visions of Daniel and John, $1842^{15}$

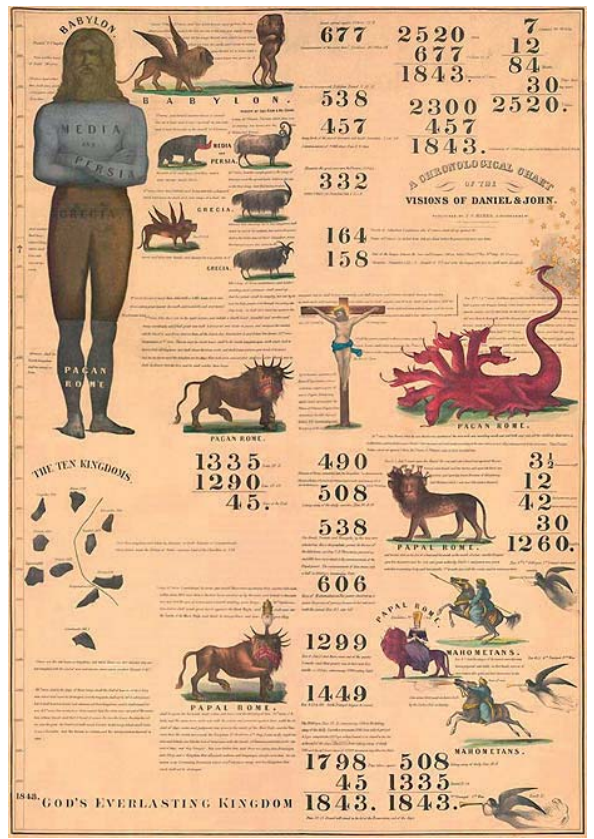

Figura 3: James White. A pictorial ilustraiton of the visions of Daniel and John, $1863^{16}$

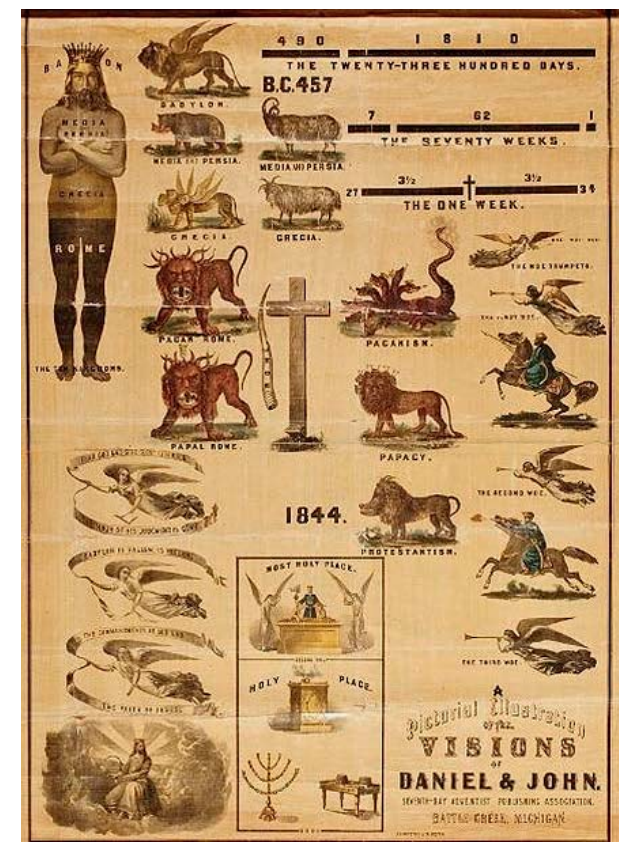

Quem compara as duas versões do gráfico cronológico atribuídos a Miller com o PDadS identifica alguns elementos visuais em comum, como a figura que representa o sonho de Daniel e as representações figurativas de nações e confissões por animais. Entretanto, eles chegam em Olson pela mediação da obra Verdade Dispensacionalista do batista Clarence Larkin (1850-1924), publicada em 1920. Seu subtítulo "Plano de Deus e Propósito ao longo das Eras" lembra em muito o título do livro de Olson, "O plano divino através dos séculos". Na sua obra, Larkin

${ }^{15}$ MILLER, William. A chronological chart of the visions of Daniel and John. Boston: Thayer Cos. Lith., [1843]. In: Página do Independent. Disponível em: < https:// static.independent.co.uk/s3fs-public/thumbnails/image/2014/10/16/18/5747953. jpg?w968 >. Acesso em: 20 abr. 2019.

16 WHITE, James. "A pictorial illustration of the visions of Daniel and John”. In: Página Bible Picture Pathway. Disponível em: < http://www.biblepicturepathways.com/ the-1863-prophecy-chart.php >. Acesso em: 20 abr. 2019. 
apresenta um número significativo de cento e quinze gráficos, mapas e litografias, visualizando elementos isolados como uma serpente, motivos parciais um pouco mais complexos, como os retratos das sete dispensações em círculos repletos de elementos figurativos ${ }^{17}$, até esquemas mais abrangentes que combinam elementos e motivos com gráficos cronológicos $^{18}$.

Figura 4: Clarence Larkin. Verdade Dispensacionalista, 1920. p. 148 [“O livro de Daniel"] ${ }^{19}$

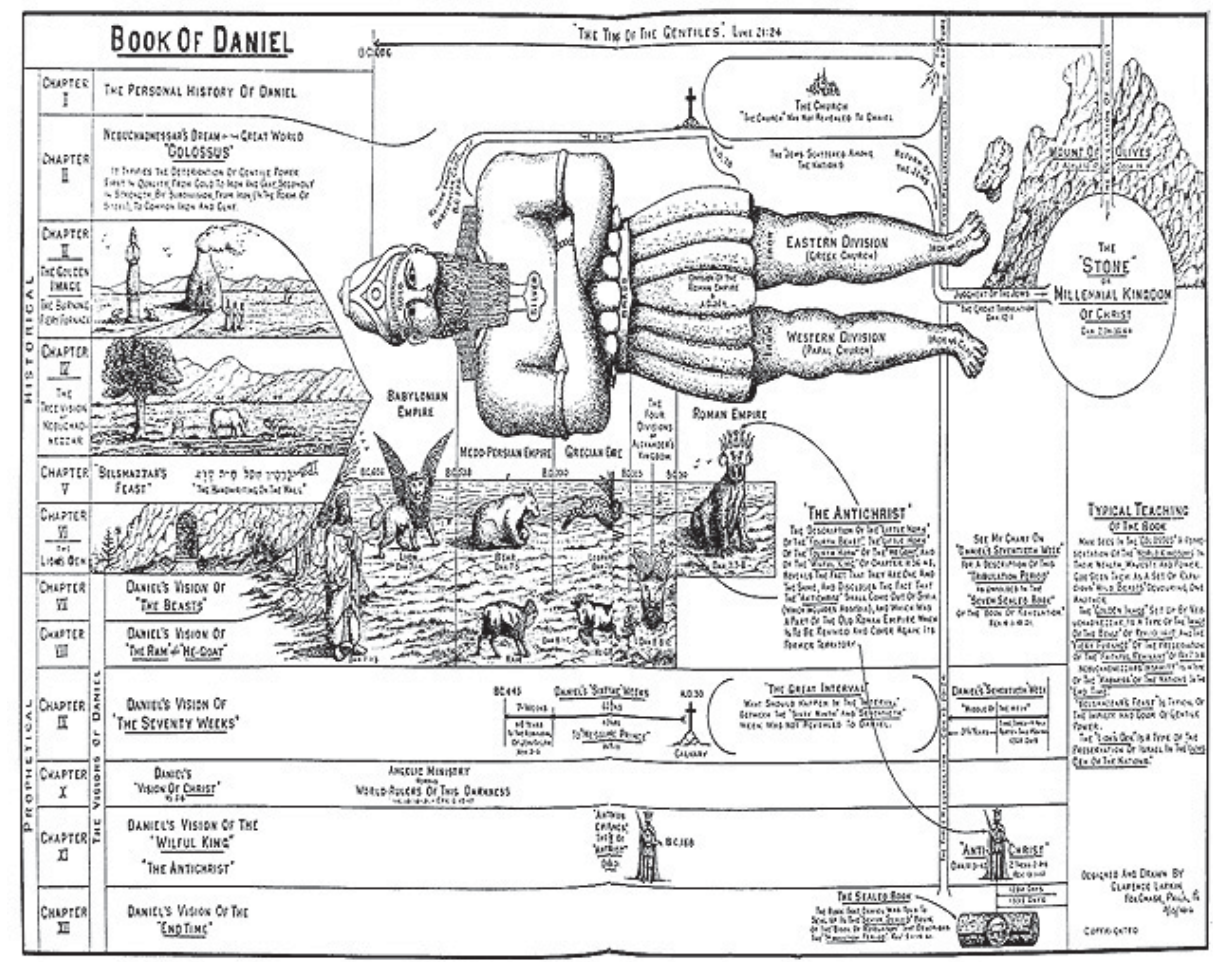

${ }^{17}$ LARKIN, Clarence. Dispensational Truth or God's Plan and Purpose in the Ages. 2 ed. ampliada. Glenside, PA, 1920, p. 53, 55.

18 Trata-se dos esquemas: "As sete fases cósmicas da terra" (LARKIN, 1920, p. 64); "O livro de Daniel" (LARKIN, 1920, p. 147); "Dividir a palavra da verdade de forma adequada” (LARKIN, 1920, p. 148); “O reino” (LARKIN, 1920, p. 149).

${ }^{19}$ LARKIN, Clarence. Dispensational truth, 1920. p. 148: Chart "The book of Daniel”. In: Página The Eternal Circle. Disponível em: < https://www.theeternalcircle.net/ clarence-larkin-dispensational-truth/ > . Acesso em: 20 abr. 2019. 
Outro exemplo de uma proposta para um esquema dispensacionalista envolvendo motivos e figuras em número significativo anterior à proposta de Olson era um gráfico de profecias do então assembleiano Finis Jennings Dake (1902-1987), criado em 1927, chamado O plano das eras (figura 5). Tanto a obra de Dake como a obra de Larkin são referenciados na obra de Olson, ou seja, Olson estabelece uma linhagem entre essas obras e seus gráficos ou cartazes dispensacionalistas e seu $P D a d S^{20}$. No banco de dados worldlcat encontra-se um livro com o nome do gráfico do ano de 1949, mas na página do Flower Pentecostal Heritage Center que se encontra no Centro Administrativo Nacional da Assemblies of God há uma cópia pintada em tamanho maior, de 1931, criada pelo missionário assembleiano Carl D. Holleman (1911-2001), que a usou na sua missão na Índia. Nessa página, afirma-se também que o original teria sido criado em 1927.

Figura 5: Fins Jennings Dake. The Plan of The Ages, $1927^{21}$

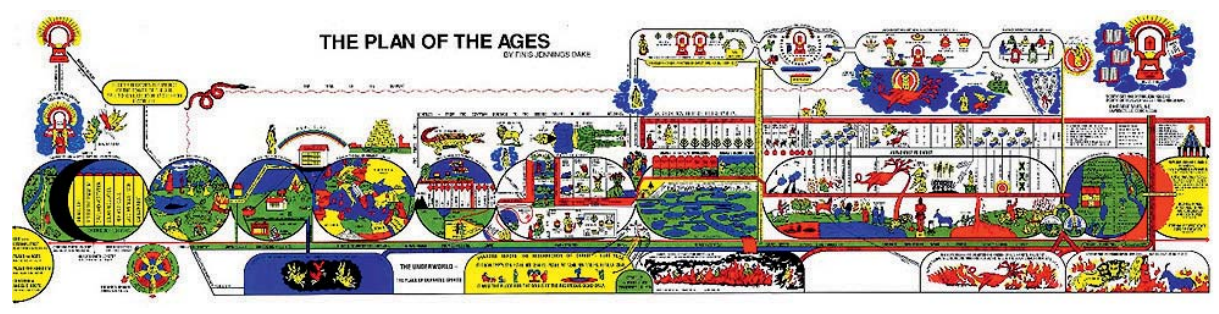

O plano também acompanhava a edição estadunidense da Bíblia de Referência Dake, lançada em 1963 com 35.000 notas ou comentários

20 “As obras consultadas na preparação desta matéria tão palpitante para os crentes em Jesus, vivendo nos dias atuais que precedem o iminente regresso de Jesus Cristo à terra, são: Dispensational Studies, por Ralph M. Riggs, e Ages and Dispensations, por Frank M. Boyd, autores que eram meus professores no Central Bible College em Springfield, Missouri, EUA. Outras obras incluem Dakes Annotated Bible, The Schofield Bible, Strong's Concordance, Bible Dictionary, por Merril F. Unger, e Dispensational Truth, por Clarence Larkin" (OLSON, Lawrence Nelson. O Plano Divino Através dos Séculos. Rio de Janeiro: CPAD, 2013, p. 7). Dake e Larkin são então obras que ele conhece depois dos seus estudos.

${ }^{21}$ DAKE, Fins Jennings. The Plan of the Ages, 1927. In: página da Ray of Hope Church. Disponível em: < http://www.rayofhopechurch.com/dake1.htm >. Acesso em: 20 abr. 2019. 
do autor. ${ }^{22}$ A CPAD, posteriormente, junto com a Editora Atos, lançaria uma versão brasileira, chamada Bíblia Anotada Dake, porém com um número reduzido das notas. Essa edição, porém, não foi lançada com o plano original de Dake, mas com o PDadS (figura 6).

Figura 6: Bíblia Anotada Dake, encarte da edição brasileira: o PDadS ${ }^{23}$

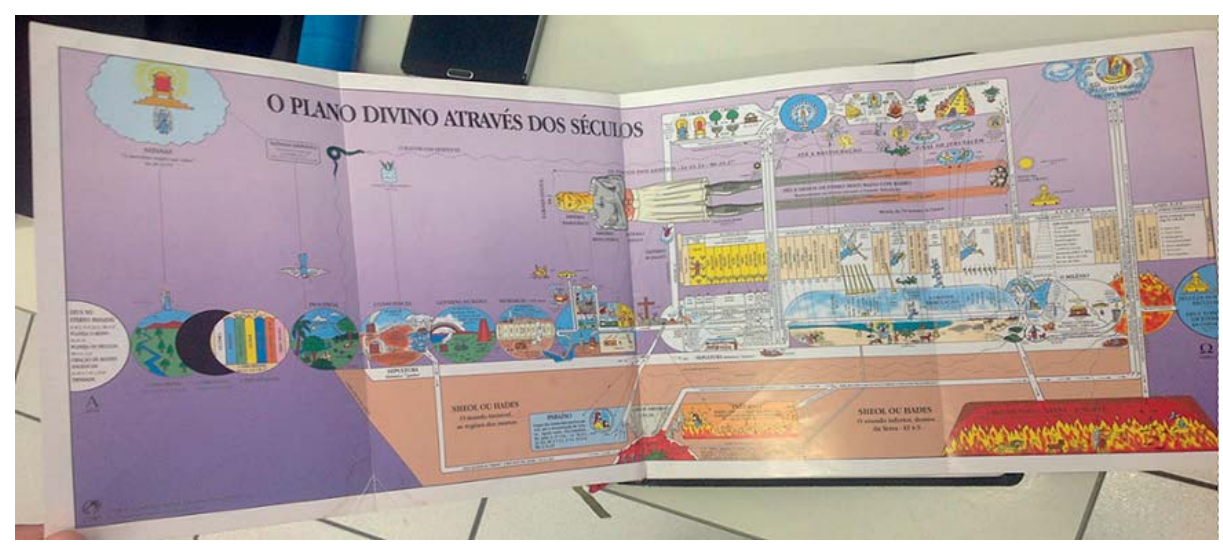

Não se deu ou dá nenhuma satisfação para essa alteração, mas, eventualmente, trata-se do simples problema do avanço da história: enquanto Larkin lidou com o fim da I Guerra Mundial, Dake antecipa por um ano a crise do Black Friday da bolsa de Nova York e Olson escreve em meio da II Guerra Mundial. ${ }^{24}$ Em todas essas épocas mudam também os agentes, especialmente "do mal", o que requer uma atualização das profecias referente aos acontecimentos mais contemporâneos. Quanto aos elementos e motivos visuais, uma comparação dos dois encartes revela elementos visuais quase idênticos, como por exemplo, a serpente na parte superior direito, mas também diferenças de dimensões como o tamanho da figura que representa do sonho de Daniel e a substituição do retrato de um mapa com países por outro motivo.

${ }^{22}$ No Brasil houve uma edição conjunta da Bíblia Anotada Dake pelas editoras ATOS e CPAD, porém, a CPAD incluiu nessa edição o PDasD de Olson (figura 6) e não o mapa do Dake (figura 5).

${ }^{23}$ Bíblia Anotada Dake. O PDadS com encarte da edição brasileira. Foto: Eric Martin.

${ }^{24}$ Repare-se do modelo de um tanque que aparece no seu mapa, em 1943, uma das armas mais modernas e decisivas. 
Olson desenvolveu seu PDadS tanto das ilustrações de Larkin como do "mapa" de Dake e, por meio de Larkin, também de Miller e White. ${ }^{25}$ Não entramos nas iconografias específicas de cada esquema, ${ }^{26}$ mapa ou gráfico dispensacionalista, mas fica evidente como Olson baseia-se numa tradição que vincula a narrativa textual dispensacionalista com uma linguagem visual quando cria sua visualização da doutrina dispensacionalista. Em 1943, essa linguagem visual apocalíptico-dispensacionalista com suas expressões adventista (Miller, White), batista (Larkin) e pentecostal assembleiana (Dake) tinha acumulado os seus primeiros 100 anos. Quando o missionário assembleiano estadunidense Olson chega no Brasil, em 1938, repete em 1943 o que o missionário assembleiano estadunidense Carl D. Holleman (1911-2001), escalado para Índia, fez em 1931: criar um mapa dispensacionalista para a missão; ${ }^{27}$ entretanto, se ele tinha o conhecimento da obra de Holeman ou não, fica em aberto. Claro é que tanto Holeman com Olson entenderam que a divulgação das convicções dispensacionalistas seria um elemento chave na promoção da missão e que essa exposição podia ser acompanhada por meios da cultura visual. Eventualmente, podemos até dizer: enquanto o problema dos diferentes idiomas na missão no pentecostalismo primitivo conta com a glossolalia para a tradução, nas décadas posteriores o papel das explanações em culturas com um baixo grão de alfabetização assume uma expressão da cultura visual.

${ }^{25}$ Quanto à cronologia, Olsen se baseia numa edição estadunidense de Henry Browne (1844) que sua vez baseia em Fynes Clinton (1834a, 1834b, 1834-1850).

${ }^{26}$ Cada autor mencionado junta aspectos muitos diversos que os estudos da cultura visual sozinhas também não são capazes de captar na sua totalidade. Como exemplo, podemos mencionar o autor Dake. Entre as suas diversas publicações focadas na teoria dispensacionalista, encontra-se também uma publicação racista: Trinta razões a favor da segregação das raças. Seria um exercício importante de cruzar as referências bíblicas desse tratado com as notas da Bíblia Anotada Dake (edição brasileira) e da Annotated Reference Bible (edição estadunidense) referente aos mesmos versículos ou perícopes.

${ }^{27}$ Hoje o mapa é vendido em três tamanhos: $1,20 \mathrm{~m}$ x 5.20m; 0,60m x 2.70m; 0,23m x $107 \mathrm{~m}$. Com outras palavras: mantém a prática de aulas. 


\section{Papel eclesial do cartaz dispensacionalista " $O$ plano divino através dos séculos"}

Nas Assembleias do Brasil, através da Casa Publicadora das Assembleias de Deus (CPAD), instituição que Olson também ajudou fundar, o PDadS foi primeiro vendido como encarte do livro com o mesmo nome, mas suas edições posteriores não mais o disponibilizam. Entretanto, não se esquece a relação inicial entre livro e mapa cronológico. Assim, essas edições vendidas sem o plano estabelecem uma relação entre o livro e o plano como ferramenta auxiliar para poder acompanhar melhor os estudos propostos, referindo-se continuamente ao PDadS. Em seguida damos um de dezenas de exemplos encontrados no livro:

Capítulo 9

O século presente

A Segunda Vinda de Cristo

F. A Igreja e a Segunda Vinda de Cristo

O leitor deve localizar este período no Mapa das Dispensações ${ }^{28}$.

Todavia, enquanto o livro se refere frequentemente ao PDadS, o próprio PDadS agora vendido como cartaz em diferentes tamanhos, não faz menção nenhuma ao livro. Com a separação, o PDadS e sua linguagem religiosa visual ganharam autonomia da linguagem religiosa textual. ${ }^{29}$ Para essa crescente autonomia contribuiu provavelmente também o fato que a CPAD acrescentou à edição da Bíblia Anotada Dake o PDadS de Olson e não o esquema proposto por Dake. Para o/a leitor/a brasileiro/a assembleiano/a, o PDadS se tornou a partir dos meados da década de 1940 e mais uma vez reforçado na década de 1970 um discurso visual exclusivo que obteve o monopólio tanto entre os/as estudiosos/as do dispensacionalismo, mas também os/as leitores/ as da Bíblia. ${ }^{30}$

${ }^{28}$ OLSON, 2013, p. 153.

${ }^{29}$ O mesmo ocorreu com a Bíblia anotada Dake.

${ }^{30}$ A edição de Dake, acompanhada pela edição da Almeida Revista e Corrigida, deve ser uma das primeiras edições de bíblias pentecostais - depois da Bíblia Scofield - o que deve ter garantido a ela uma recepção maior nos lares pentecostais. 
Aqui temos dois detalhes importantes que contribuíram para a divulgação do PDadS nas Assembleias de Deus e sua fixação no imaginário religioso denominacional, os ensinos contínuos sobre a doutrina apocalíptico-dispensacionalista dentro das igrejas e dos lares dos seus membros, como, por exemplo, em sala de aula da escola dominical ${ }^{31}$, e o estudo pessoal da bíblia. Com a separação do PDadS do livro com o mesmo nome, o PDadS ganhou também em formato e o quadro se tornou cartaz. Em muitas igrejas ele recebeu um espaço permanente, ou seja, de destaque, em formato de quadro com moldura de madeira e vidro para a sua proteção. Esses quadros do PDadS se encontravam e encontram em diversas igrejas assembleianas e não representam uma noção ou função estética, mas pedagógica. O PDadS e sua linguagem religiosa visual acabou sendo o meio mais importante para apresentar e explicitar a doutrina dispensacionalista. Mas isso vai além da transmissão de informações. Como Tamar Gordon, em sua Introdução às culturas visuais pentecostais de 2002 anota, qualquer artefato visual contribui para a formação de comunidades imaginadas:

Os artefatos visuais fazem mais do que divulgar, como os milagres da saúde, prosperidade e conversão ao espírito são operados na vida cotidiana. Eles também impulsionam o público para comunidades imaginadas onde há evidências tangíveis do espírito que opera através de pessoas, aldeias, bairros, cidades, nações e o mundo ${ }^{32}$.

Agora, o PDadS não é qualquer artefato visual na Igreja Assembleias de Deus, mas o artefato. Em formato de quadro permanente, o PDadS estabeleceu um padrão visual e fixou as convicções dispensacionalistas como algo essencial para a Igreja Assembleias de Deus no imaginário assembleiano.

Que historiador das religiões se contentaria em consultar os tratados de teologia ou as recolhas de hinos? Ele sabe bem que sobre as

${ }^{31}$ Dominado na Igreja Assembleias de Deus "Escola Bíblica Dominical”.

32 GORDON, Tamar. "Introduction: visual culture of Pentecostalism". Material Religion, vol. 1, n. 3, jul./set. 2011, p. 310. 
crenças e as sensibilidades mortas, as imagens pintadas ou esculpidas nas paredes dos santuários, a disposição e o mobiliário das tumbas, tem pelo menos tanto para lhe dizer quanto muitos escritos ${ }^{33}$.

Isso ocorre especialmente quando esses artefatos são regulamente usados e apresentados a todas as idades, todos os membros e todos/as ingressos/as. E isso era e é o caso. O PDadS em formato de quadro assumiu um papel fundamental em escolas dominicais, cultos de ensino e em conferências escatológicas. Abaixo um chamado para os estudos do PDadS na interface da esfera pública e eclesiástica:

Nos dias 28, 29, 30 e 31/08, a Igreja Evangélica Assembleia de Deus de Caçador receberá em seu templo Sede o Pastor Nirton dos Santos, presidente de honra da CIADESCP - Convenção das Igrejas Evangélicas Assembleia de Deus de Santa Catarina e Sudoeste do Paraná. [...] Pastor Nirton ministrará o estudo "Plano Divino Através dos Séculos", no qual o participante poderá entender as diversas Alianças de Deus com a humanidade, também as diversas Dispensações pelas quais Deus trabalhou na salvação do homem e ainda receber a oração dos pastores da Igreja. O estudo vai iniciar na sexta-feira (28) às $19 \mathrm{~h} 30$, continua no sábado (29), também às $19 \mathrm{~h} 30$ e vai até o domingo (30) às 19h00. Durante os três dias as palestras serão gratuitas e abertas ao público. [...] Você que deseja aprender mais sobre a Origem do Ser Humano, o Desenvolvimento da História da Humanidade e sobre o que Acontecerá no Final dos Tempos, este evento é uma excelente oportunidade de aprofundamento intelectual, bíblico e teológico (UNIÃONET.COM, s/p).

O estudo do PDadS requer, então, tempo e dedicação, no caso, três econtros noturnos de sexta-feira a domingo.

\footnotetext{
${ }^{33}$ BLOCH, M. Apologie pour l'histoire ou métier d'historien. Paris: Colin, 1949, p. 34.
} 
Figura 7: Pastor Nirton Dos Santos das

Assembleias de Deus falando sobre o PDadS $^{34}$

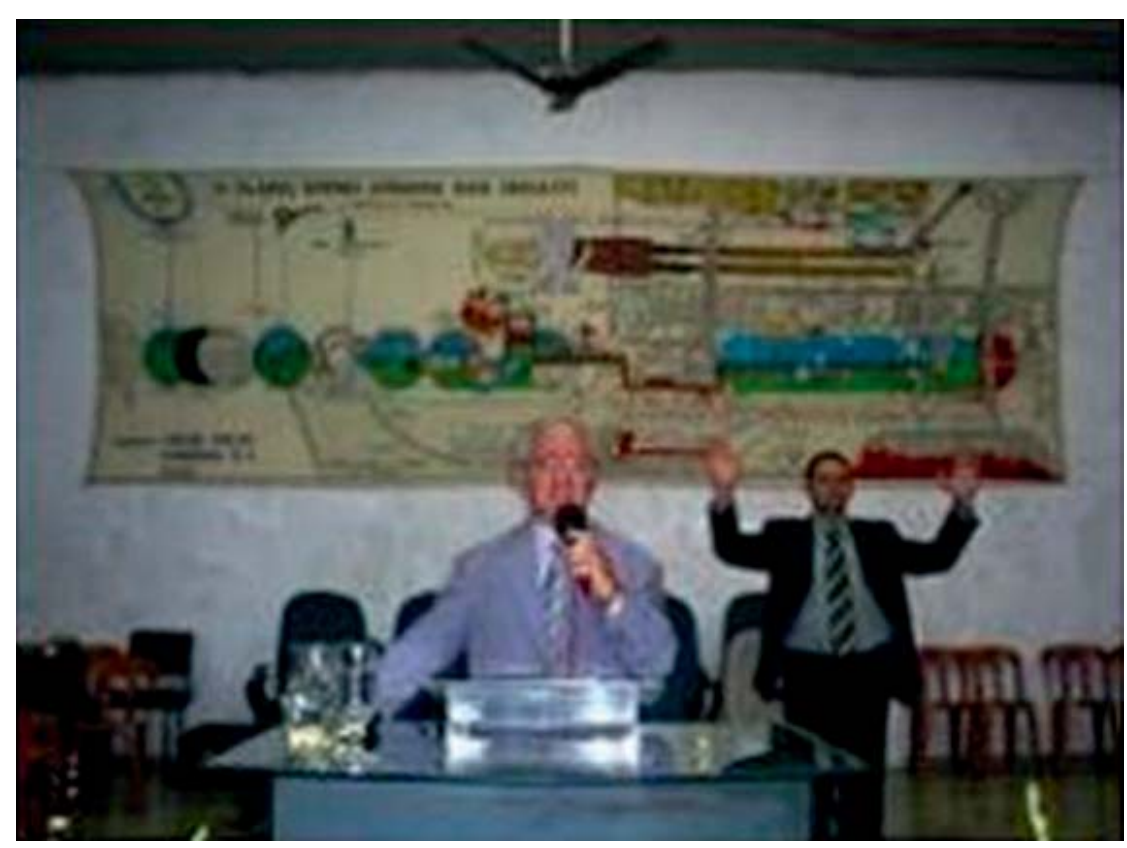

No caso, trata-se de uma evento público que é apresentado como "uma excelente oportunidade de aprofundamento intelectual, bíblico e teológico" para os adeptos e uma possibilidade para "aprender mais sobre a Origem do Ser Humano, o Desenvolvimento da História da Humanidade e sobre o que Acontecerá no Final dos Tempos" para o público geral. Obviamente trata-se de um estudo considerado chave, tanto para iniciantes como para adeptos - que aparentemente não devem somente uma vez, ou seja, incialmente, passar pelo estudo, mas, de forma contínua. Deve-se explorar as sutilezas do dispensacionalismo e, no centro desse estudo, encontra-se um artefato visual de criação pentecostal de tamanho expressivo, fixado na parede (no caso parece ser uma impressão em tecido).

${ }^{34}$ O Pastor Nirton do Santos interpreta o "Plano Divino Através dos Séculos" na década de 60. In: página Memórias das Assembleias de Deus. Disponível em: < http://mariosergiohistoria.blogspot.com >. Acesso em: 03 nov. 2018. 
Em comunidades menores, pode se usar o PDadS de forma mais simples, em formato menor, colado num fundo de madeira, como pode ser visto no screenshot de um vídeo do pastor Vicente de Paula da Igreja Evangélica Assembleia de Deus - Missões- Campo (figura 8).

Figura 8: Pastor Vicente de Paula ensina

“O Plano Divino através dos Séculos", 201135

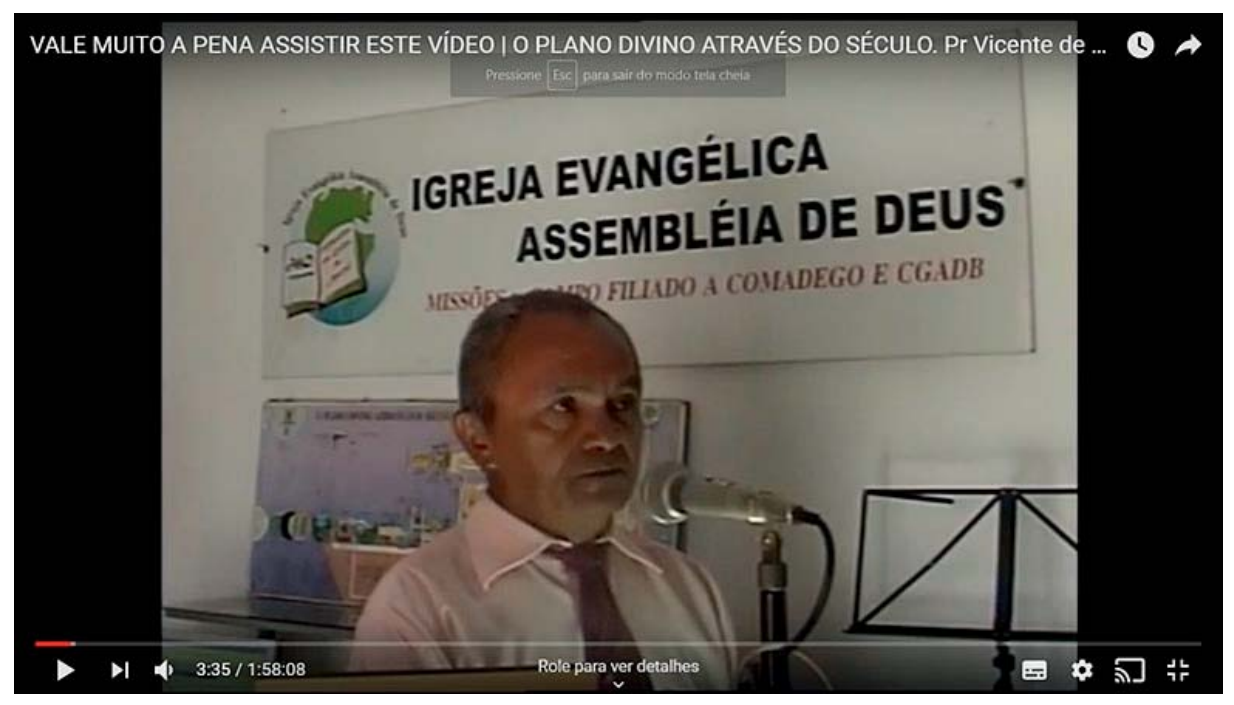

Nessa imagem, aparece o plano no fundo da imagem encostado num tipo de balcão, abaixo a placa da Igreja. Provavelmente, o plano passa no estudo de mão em mão ou é colocado em uma mesa para estudá-lo e assimilá-lo.

Na próxima imagem, aparece um tamanho intermediário entre os dois planos já apresentados, agora fixado num quadro de anúncios (figura 9). Em todos os casos pode-se perguntar se os diferentes auditórios realmente são capazes de enxergar os detalhes. Se não for o caso, o plano se torna mais uma só imagem.

35 O Pastor Nirton do Santos interpreta o "Plano Divino Através dos Séculos" na década de 60. In: página Memórias das Assembleias de Deus. Disponível em: $<$ http://mariosergiohistoria.blogspot.com >. Acesso em: 03 nov. 2018. 
Figura 9: Pastora Donizete da Igreja Quadrangular explica o PDadS, $2017^{36}$

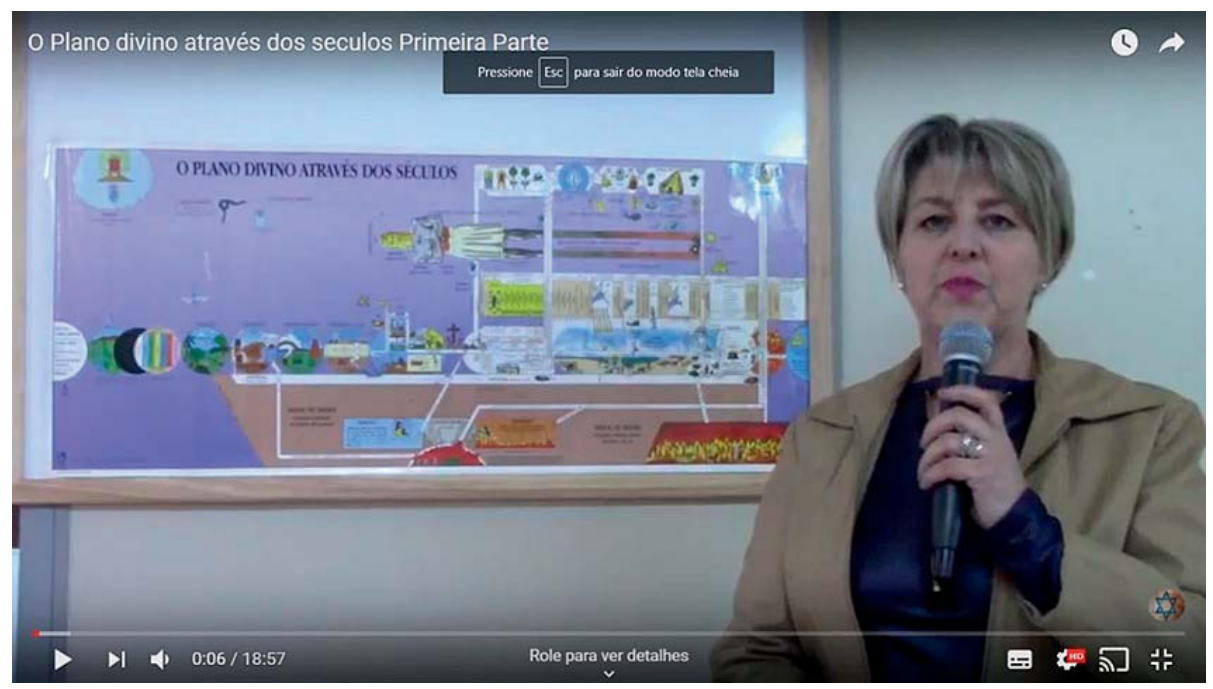

Vistas juntas as figuras 8 a 10, estabelece-se uma ideia bastante clara de como o imaginário dispensacionalista assembleiano - e além, como a figura 9 demonstra - se associou em especial ao quadro do PDadS. Houve uma fusão entre doutrina, artefato visual e imaginário.

Além disso, pode-se ainda mencionar um caso específico vivenciado, o da Igreja Assembleia de Deus em Santo André, SP. Essa comunidade tinha o quadro desde a década de 50. Atualmente, ele se encontra na Igreja Assembleia de Deus em Santo André, na Vila Humaitá, uma filial. Esse quadro continua sendo em exposição contínua e está disponível para consulta. Em todos os estudos que remetem às dispensações, a estátua do sonho de Daniel, o estudo sobre o Fim dos Tempos ou Escatologia em geral continua sendo usada. Esse uso se concentra principalmente na EBD (Escola Bíblica Dominical), que acontece todos os domingos. O descolamento do plano do livro tinha, porém, mais um efeito importante e essencial pela sobrevivência do próprio plano: a partir da separação, as profecias concretas não precisavam mais ser corrigidas em um livro.

${ }^{36}$ Foto do vídeo Pastora Donizete interpreta o "O Plano Divino através dos Séculos". In: Youtube: Publicado em 16 ago. /2017. Disponível em: < https://www.youtube. com/watch?v=YFZQ8IpzeLc >. Acesso em: 20 abr. 2019. 
Consequentemente, o PDadS - um esquema de 1943 - sofreu um desgaste de credibilidade bem menor por ser ausentado da necessidade de atualizações contínuas como aconteceu, por exemplo, com os livros de Hal Lindsey, já que a história tomou outros rumos do que do aqueles previstos por ele, por um lado, e acabou, por outro lado, pelo surgimento de novos agentes no cenário global. A passagem da linguagem textual para a linguagem visual possibilitou atualizações orais contínuas, sem a necessidade de modificar a representação visual do plano em si.

\section{Considerações finais}

O PDadS moldou o imaginário dos/as adeptos/as das Assembleias de Deus no Brasil. Ele representa um elemento essencial da cultura visual pentecostal brasileira, com ecos que vão além das Igrejas Assembleias de Deus. A sua aceitação se deu por diversas razões. Primeiro, especialmente para a promoção da doutrina dispensacionalista, pois já se tinha criado uma tradição centenária do vínculo entre narrativas religiosas textuais e linguagens religiosas visuais. Segundo, aparecia-se o aspecto visual justamente nas missões, entre outras razões, para superar problemas de idioma e problemas de leitura, pois desta forma os/as menos letrados/ as ou analfabetos/as poderiam acompanhar o estudo ministrado pelo/a pastor/a ou o/a líder leigo/a com mais facilidade. Terceiro, o PDadS chega no momento de uma nova fase de expansão pentecostal no Brasil e a acompanha. Entretanto, o PDadS não somente lança as ideias centrais dispensacionalistas, mas tem um efeito duplo e até antagonista. Por um lado, ele acaba acentuando e blindando aspectos da doutrina dispensacionalista, como por exemplo, a ideia de duas criações (círculo preto nas dispensações), resultado de uma leitura literalista de Gênesis 1. Por outro lado, o formato visual permite a sobrevivência da doutrina dispensacionalista pelo fato de que ele facilita contínuas atualizações orais da previsão dos cumprimentos das profecias. $\mathrm{O}$ mundo muda, as previsões do cumprimento das profecias são adaptadas, mas não há mais um texto cuja contínua atualização causa um desgaste maior - no mínimo para quem as acompanha por vinte, trinta ou quarente anos, sempre sobre o preceito da imanência do fim. 
A passagem do $P D a d S$ da promoção textual à representação visual, em combinação com a sua contínua onipresença nos ambientes assembleianos, tanto particulares (Bíblia Anotada Dake) como comunitários (Templos, corredores, entradas, espaços da Escola Bíblica Dominical) estabeleceu e sedimentou e, até um certo modo, acomodou o imaginário dispensacionalista assembleiano. Isso significa também que uma releitura das teorias dispensacionalistas assembleianas será, provavelmente, somente possível, ou em contradição ao PDadS, ou mediante da sua substituição ou da modificação ou de outras técnicas de omissão ou de esquecimento. Uma releitura, entretanto, será necessária, já que as diferenças dos mapas propostas por Miller (1843/1863, Larkin (1920), Dake (1927) e Olson (1943) lidam com cronogramas e sua vinculação com pessoas, nações e eventos históricos até a época do seu cotidiano, mas não vão além disso. Em outras palavras, quanto aos cronogramas propostos nada pode impedir seu envelhecimento no decorrer da história, mas não necessariamente quanto a sua visão da história e escatologia, onde até agentes clássicos podem perder seus papeis e assumir novos, como, por exemplo, no caso da substituição da Rússia pelo Iraque, pelo Irã ou pela China.

A omissão do Plano de todas as eras de Dake e sua substituição pelo PDadS de Olson representa um movimento até iconoclasta, já que se trata do conflito entre duas imagens destinadas a um público idêntico. No Brasil, essa omissão e ausência fática de alternativas acabou favorecendo e fortalecendo a ideia da unicidade ou singularidade do modelo proposta de Olson, o que, por sua vez, pode colocar o PDadS num patamar extraordinário. Em comparação com outras partes essenciais da doutrina pentecostal, como, por exemplo, a doutrina do batismo no ou pelo Espírito Santo, o aspecto visual pode até resultar em um peso maior atribuído ao aspecto dispensacionalista ao lado do aspecto pneumatológico. Certamente, o deslocamento do PDadS do livro foi favorecido por um tipo de inversão na subordinação da imagem ao texto, em 1943, para a possiblidade da subordinação do texto à imagem: o livro, aparentemente, não pode existir sem o plano, mas o plano acaba conquistando o tempo, o espaço e os corações, independentemente do texto. Consequentemente, as Igrejas Assembleias de Deus podem ser identificadas com o PDadS assim como as Igrejas Protestantes históricas podem ser identificadas com a imagem dos dois caminhos de Charlotte Reihlen. 


\section{Referências}

BLOCH, M. Apologie pour l'histoire ou métier d'historien. Paris: Colin, 1949.

BROWNE, Henry. Ordo Saeculorum: A Treatise on the Cronology of The Holy Scriptures: And The Indications Therein Contained. Divine Plano of Times and Seasons: Together With an Appendix". London: J.W. Parker, 1844.

CLINTON, Henry Fynes. Fasti Hellenici: the Civil and Literary Chronology of Greece from the 55th to the 124th Olympiad. Oxford: Oxford at the University Press, 1834. [Coletânea Fasti Hellenici, vol. 1] . Fasti Hellenici: the civil and literary chronology of Greece, from the earliest accounts to the death of Augustus. Oxford: Oxford at the University Press, 1834. [Coletânea Fasti Hellenici, vol. 2] . Fasti Romani, the Civil and Literary Chronology of Rome and Constantinople from the Death of Augustus to the Death of Heraclius. Oxford: Oxford at the University Press, 1834-50. 2. vol.

DAKE, Finis Jennings. Bíblia Anotada Dake. Curitiba, PN: ATOS, 2011. . Bíblia de Estudo Dake. Curitiba, PN: ATOS, 2011.

. Dake's annotated reference Bible: the Holy Bible, containing the Old and New Testaments of the Authorized or King James version text ... and a complete concordance and cyclopedia index. Lawrenceville, Ga.: Dake Bible Sales, 1963. [A última edição de 2013 usa a New King James Version].

The plan of the ages. Atlanta, GA: Finis Jennings Dake, 1949. "Prophecy charts". In: Página da Flower Pentecos-

tal Heritage Center. Disponível em: < https://ifphc.wordpress. com/2015/08/19/original-1931-prophecy-chart-by-finis-jennings-dake-deposited-at-heritage-center/ > . Acesso em: 20 abr. 2019.

Thirty reasons for segregation of races. In: Página do

The Ten Commmandment Ministry. Disponível em: < https://thetencommandmentsministry.us/ministry/blog/ articles/30-reasons-for-segregation-of-races/ > . Acesso em: 20 abr. 2019.

FERREIRA, Maycon Sanches; OLIVEIRA, Vilmar Diniz; OLIVEIRA, David Mesquiat; SERENO, Samuel Goulart; SOUSA, Antonio Junio Alves de. "O Dispensacionalismo no Pentecostalismo Brasileiro: 
Introdução ao Estudo de Recepção da Obra O Plano Divino Através dos Séculos". Unitas - Revista Eletrônica de Teologia e Ciências das Religiões, Vitória-ES, v. 4, n. 2, p. 155-172, 2016.

GORDON, Tamar. "Introduction: visual culture of Pentecostalism". Material Religion, vol. 1, n. 3, p. 308-313 (jul./set. 2011).

LARKIN, Clarence. Dispensational Truth or God's Plan and Purpose in the Ages. 2 ed. ampliada. Glenside, PA, 1920.

MARTINS, Eric de Oliveira. Cultura visual pentecostal: presença e uso do Quadro "o plano divino através dos séculos numa igreja Assembleia de Deus”. 2019. 149f. Dissertação (Mestrado em Ciências da Religião) Universidade Metodista de São Paulo, Bernardo do Campo, SP.

MORGAN, David. The forge of vision: a visual history of modern Christianity. Oakland: University California Press, 2015.

NOVAES, Allan Macedo de. In: "Uma breve história da cultura visual adventista nos anos 1830 a 1860: o uso de imagens religiosas por um movimento de orientação textocentrada". Numen, revista de estudos e pesquisa da religião, Juiz de Fora, RJ, p. 38-61, 2018.

OLSON, Lawrence Nelson. O Plano Divino Através dos Séculos. Lavras, MG: [s.e.], 1943.

OLSON, Lawrence Nelson. O Plano Divino Através dos Séculos. Rio de Janeiro: CPAD, 2013.

SACHALY, Harald. O Pré-milenismo Dispensacionalista à luz do Amilenismo. 2 ed. Rio de Janeiro: Junta de Educação Religiosa e Publicações, 1987.

UNIÃONET.COM. Igreja Evangélica Assembleia de Deus. SIMECC. Disponível em: < https://www.uniaonet.com/ieadcacadorsc.htm>. Acesso em: 20 nov.2018.

\section{Referencias imagéticas}

Figura 1: OLSON, Nelson Lawrence. O plano divino através dos séculos, 1943 [cartaz]. Do acervo pessoal dos autores.

Figura 2: MILLER, William. A chronological chart of the visions of Daniel and John. Boston : Thayer Cos. Lith., [1843]. In: Página do Independent. Disponível em: < https://static.independent.co.uk/s3fs- 
public/thumbnails/image/2014/10/16/18/5747953.jpg?w968 >. Acesso em: 20 abr. 2019.

Figura 3: James White. "A pictorial illustration of the visions of Daniel and John". In: Página Bible Picture Pathway. Disponível em: $<\mathrm{http}: / /$ www.biblepicturepathways.com/the-1863-prophecy-chart.php >. Acesso em: 20 abr. 2019.

Figura 4: LARKIN, Clarence. Dispensational truth, 1920. p. 148: Chart "The book of Daniel". In: Página The Eternal Circle. Disponível em: < https://www.theeternalcircle.net/clarence-larkin-dispensationaltruth/ > . Acesso em: 20 abr. 2019.

Figura 5: DAKE, Fins Jennings. The Plan of the Ages, 1927. In: página da Ray of Hope Church. Disponível em: < http://www.rayofhopechurch.com/dake1.htm >. Acesso em: 20 abr. 2019.

Figura 6: Bíblia Anotada Dake. O PDadS com encarte da edição brasileira. Foto: Eric Martin.

Figura 7: O Pastor Nirton do Santos interpreta o "Plano Divino Através dos Séculos" na década de 60. In: página Memórias das Assembleias de Deus. Disponível em: < http://mariosergiohistoria.blogspot.com >. Acesso em: 03 nov. 2018.

Figura 8: Foto do vídeo Pastor Vicente de Paula interpreta o "O Plano Divino através dos Séculos" na Igreja Evangélica Assembleia de Deus em Missões. In: Youtube. Publicado em: 8 jul. 2017. Disponível em: < https://www.youtube.com/watch?v=KM25ir-f05Q >. Acesso em 03/10/2018.

Figura 9: Foto do vídeo Pastora Donizete interpreta o "O Plano Divino através dos Séculos". In: Youtube: Publicado em 16 ago. /2017. Disponível em: < https://www.youtube.com/watch?v=YFZQ8IpzeLc $>$. Acesso em: 20 abr. 2019. 